\title{
Analysis of C3 fraction splitting system performance by mathematical modeling in MATLAB environment
}

\author{
Miroslav Variny ${ }^{\text {a }}$, Patrik Furda ${ }^{\text {a }}$ \\ Norbert Kováč ${ }^{b}$ Otto Mierka ${ }^{a}$ \\ ${ }^{a}$ Slovak University of Technology, Faculty of Chemical and Food Technology, \\ Department of Chemical and Biochemical Engineering, \\ Radlinského 9, 81237 Bratislava, Slovak Republic \\ ${ }^{b}$ SLOVNAFT, a.s. Vlčie hrdlo 1, 82412 Bratislava, Slovak Republic \\ miroslav.variny@stuba.sk
}

\begin{abstract}
Propane-propylene mixture splitting by industrial conventional rectification incorporating a heat pump for energy intensity decrease was modeled in the Matlab environment. The constructed model was verified by comparing its results with operational data of a real C3 fraction splitting unit. As documented, increased product quality can be obtained at zero additional costs due to specific features of the system design. Process capacity and product purity limitations have to be considered in future C3 fraction production increase plans. Further compressor and its driving unit design features have to be incorporated in the calculation model to reliably assess the C3 fraction processing costs and provide a reliable tool for process operation optimization.
\end{abstract}

Key words: C3 fraction, industrial heat pump, mathematical modeling, product purity

\section{Introduction and study objectives}

Refining and petrochemicals production belong to energy intensive industry sectors, accounting for more than $7 \%$ of the total industrial energy consumption in the OECD countries in 2012 (EIA 2016) and predicted to keep this share at least until 2040. Similarly, the share of chemical industry sector including refining and petrochemicals production on the total industrial energy demand was more than $15 \%$ in Slovak Republic in 2011 (Vall, 2011). Facing the expected decrease in fossil fuel demand for individual transportation, many refining companies, including MOL GROUP, focus their attention on new technologies implementation and material and energy efficiency improvement in those expected to continue playing a key role in their future business (MOL, 2016).

The issue of refining industry energy intensity decrease has been tackled in numerous studies in recent years. Many published studies, including Alhajji and Demirel (2015); Al-Rowaili and Ba-Shammakh (2017), and Li et al. (2016), apply computational modeling based both on the laws of thermodynamics and on the mass and energy balances together with heat and mass transfer equations and economic considerations. Environmental aspects are considered in the energy intensity and profit optimization calculations of entire production clusters as documented by Alhajji and Demirel (2015), Al-Rowaili and Ba-Shammakh (2017) and Morrow III et al. (2015).

Individual production units are frequent subjects of optimization calculations as well as simulations, e.g. crude distillation unit (Gadalla et al., 2015), isomerization process (Chuzlov and Molotov, 2016), isopropylbenzene production plant (Chudinova et al., 2016) or other plants (Vilarinho et al., 2016; You et al., 2016). The role of robust software for extensive calculations seems to be very important in achieving units profitability increase by operational or design changes. Best industrial practice and energy auditing procedures as established by DeCarolis et al. (2017), Hasanbeigi and Price (2010) and Worell et al. (2015) employ computational approach also in identification and reduction of process and design inefficiencies.

Traditional solutions and best practice applied in refining energy intensity decrease are summed up in recent studies by Danilov et al. (2018) and Worell et al. (2015), identifying, among others, heat driven refrigeration units, heat pipes and heat pumps as suitable technologies to achieve this goal. Several authors assessed the potential of industrial heat pumps application in the refining sector in recent research outcomes (Gadalla et al., 2015; Kazemi et al., 2016; You et al., 2016), corroborating the earlier findings of Demirel (2004) and Fonyo and Benkö (1998) together with the industrial experience of properly designed and operated industrial heat pump reducing the process energy consumption by 30 to $50 \%$ compared to traditional design. Best results have been achieved in applications where substances with similar boiling point have to be separated by rectification (Demirel, 2004; Fonyo and Benkö, 1998), such as light alkane-alkene mixtures or light isomer mixtures. Especially ethane-ethylene and propane-propylene splitters 
are frequently equipped with mechanical vapor recompression heat pumps (Morrow III et al., 2015; Variny et al., 2013; Variny et al., 2015; Worrel et al., 2015).

Earlier work of the authors compared traditional and heat pump driven propane-propylene separation units in SLOVNAFT a.s. (Variny et al., 2013). The prospective of C3 fraction production boost with the C3 splitter expected to be one possible bottleneck, the future C3 splitter operation with increased feed and/or changed feed composition has to be modeled, which represents the main objective of the presented study. To achieve this goal, a reliable and robust mathematical model of this part of the Fluid Catalytic Cracking Unit (FCC) was developed in the Matlab environment, verified on real operational data and used to predict the impact of feed quantity and quality changes on products purity and system energy intensity.

\section{Materials and Methods}

\section{Modeled system}

C3 fraction splitting can be characterized by high energy demand as the propylene-propane mixture is a close boiling mixture (Demirel, 2004). Propylene polymerization to which the produced propylene is submitted requires high purity pro- pylene (> $99.6 \%)$. To achieve this via conventional approach, numerous equilibrium stages and high reflux ratio are necessary (Demirel, 2004).

In the SLOVNAFT refinery, components of the C3 fraction are separated in two production units: Ethylene Unit and Fluid Catalytic Cracking (FCC) Unit. The Ethylene Unit operation provides sufficient amount of disposable heat for the column reboiler. Thus, the process in the Ethylene Unit is realized conventionally. On the contrary, the Propylene Recovery Unit of the FCG operates as an industrial heat pump utilizing latent heat of compressed product vapors in the column reboiler. A simplified flow scheme of the FCG C3 splitting process is provided in Fig. 1.

During normal operation, preheated feedstock (1) is delivered to the feed stage of the tray rectification column. Distillate vapors leaving the head of column (2) are led to heat pump compressor (K) driven by condensation turbine $(\mathrm{T})$. A part of the compressed vapors (5) continues to column reboiler (E1) where it condenses and the heat of condensation serves as the heat supply for the column. The excess heat is disposed of in heat exchanger (E2) cooled by cooling water. Condensate $(6,8)$ is subsequently expanded to the head pressure level in flash vessel (F). Evaporated gas phase (12) is led back to the compressor and liquid phase (9) is pumped

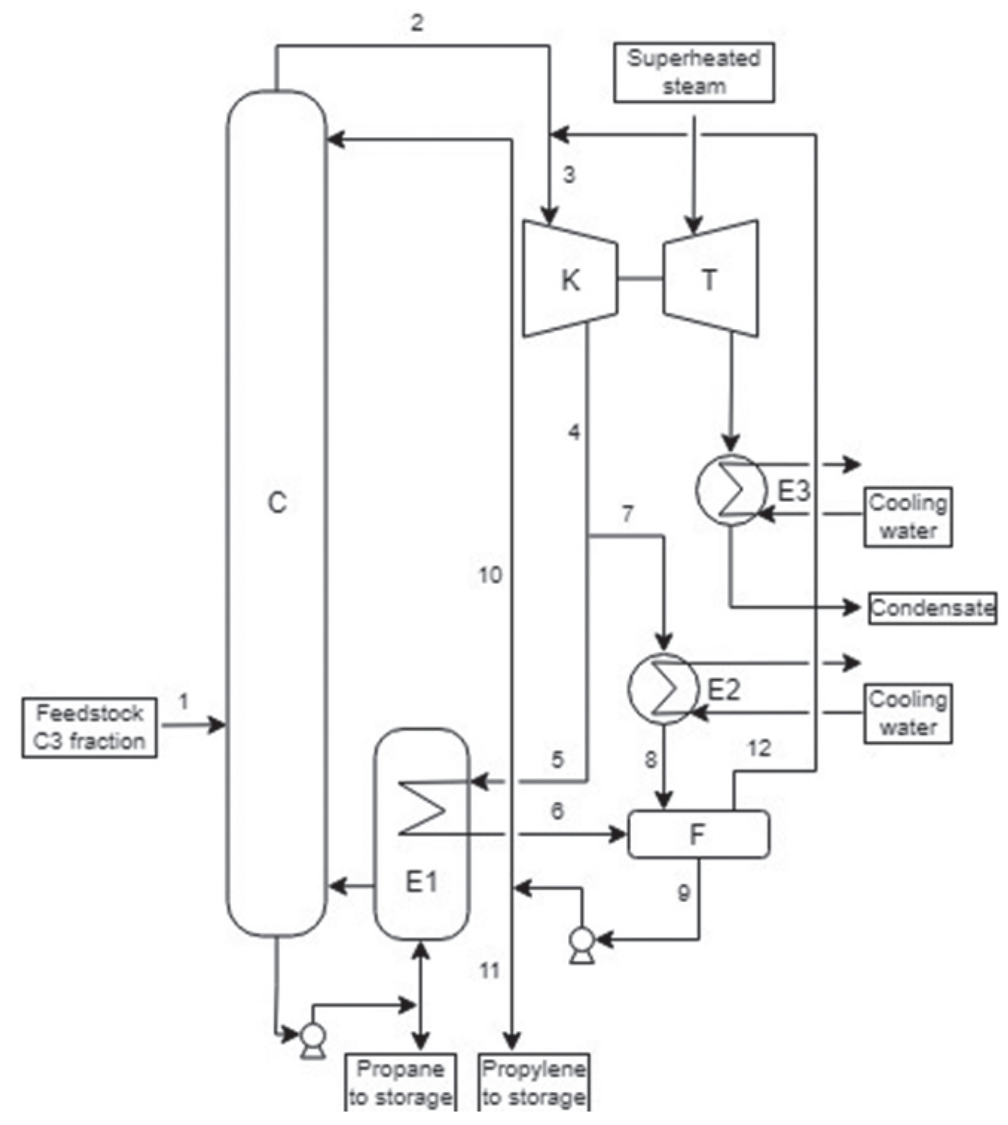

Fig. 1. Process flow diagram. 
partly as reflux to the head of the column (10) and partly as product flow (11) to storage.

\section{Mathematical model}

The model setup reflects the physical plant structure as shown in Fig. 1 and includes the following assumptions:

- Feedstock is supplied as a boiling liquid.

- Both feedstock constituents are considered to have identical molar isobaric heat capacities in liquid and in gas phase as well as identical molar heats of evaporation at constant temperature. Available data in Perry (1997) justify this simplification: molar isobaric heat capacities in the liquid phase differ by less than $7 \%$ for propane and propylene in the relevant temperature interval from 300 to $320 \mathrm{~K}$. The same conclusion was achieved for their molar isobaric heat capacities in the gaseous phase and also for molar heats of evaporation. Thus, the liquid molar flow changes only on the feed stage and that of vapor is constant along the whole column.

- Ideal gas and ideal liquid behavior is assumed.

- Pressure profile along the column is linear with no radial pressure gradient.

- There is no radial temperature gradient.

- Column reboiler operates as a total condenser and reflux enters the column as boiling liquid.

- Gaseous phase leaving each stage of the column is in thermodynamic equilibrium with the liquid phase.

- Vapor and liquid phases leaving each stage of the column are of the same temperature and composition as vapor and liquid phases at the stage, respectively.

- Heat losses in the system as well as the pressure losses in the pipelines are negligible.

The mathematical model consists of two connected parts; the first calculates the column conditions in terms of concentration and temperature profiles and energy requirements considering the assumptions formulated above and the latter calculates the heat pump performance.

Model equations (1) to (35) are provided below and the calculation diagram shown in Fig. 2a, 2b implemented in the Matlab environment provides a comprehensive overview of the calculation procedure and its complexity. Physico-chemical input data used for molar enthalpies calculation and for equations (5), (18) and (27) were obtained from Perry, 1997.

To calculate the concentration and temperature profile along the column, overall mass balance (Eq. (1) to (4)) along with balances of each stage (Eq. (8) to (13)) were calculated considering phase equilibrium at each stage (Eq. (5) to (7)). The energy balance
(14) reflects the column energy requirements. As a result, the model provides information regarding distillate mass flow and thus enables heat pump performance calculation. Alternatively, distillate composition if the heat pump performance is given.

$$
\begin{aligned}
& \dot{n}_{L, n}=R \dot{n}_{D} \\
& \dot{n}_{L, m}=\dot{n}_{F}+\dot{n}_{L, n} \\
& \dot{n}_{V}=\dot{n}_{D}+\dot{n}_{L, n} \\
& \dot{n}_{W}=\dot{n}_{F}-\dot{n}_{D} \\
& P_{i, j}^{0}=e^{\left[C 1_{i}+\frac{C 2_{i}}{T_{j}}+C 3_{i} \ln \left(T_{j}\right)+C 4_{i} T_{j}^{C 5_{i}}\right]} \\
& x_{A, j}=y_{A, j} \frac{P_{j}}{P_{A, j}^{0}} \\
& y_{B, j}=\frac{P_{B, j}^{0}}{P_{j}}\left(1-x_{A, j}\right) \\
& f v a l_{j, 1}=\dot{n}_{V} y_{A, j}-\dot{n}_{D} x_{A, j}-\dot{n}_{L, n} x_{A, j} \\
& f_{v a l} l_{j, 1}=\dot{n}_{L, n} x_{A, j-1}+\dot{n}_{V} y_{A, j+1}-\dot{n}_{L, n} x_{A, j}-\dot{n}_{V} y_{A, j} \\
& \text { fval }_{j, 1}=\dot{n}_{L, n} x_{A, j-1}+\dot{n}_{V} y_{A, j+1}+ \\
& +\dot{n}_{F} x_{F}-\dot{n}_{L, m} x_{A, j}-\dot{n}_{V} y_{A, j} \\
& f_{v a l}{ }_{j, 1}=\dot{n}_{L, m} x_{A, j-1}+\dot{n}_{V} y_{A, j+1}-\dot{n}_{L, m} x_{A, j}-\dot{n}_{V} y_{A, j} \\
& f v a l_{j, 1}=\dot{n}_{L, m} x_{A, j-1}-\dot{n}_{W} x_{A, j}-\dot{n}_{V} y_{A, j} \\
& \mathrm{fval}_{j, 2}=y_{A, j}+y_{B, j}-1 \\
& \dot{Q}_{R B}=\dot{n}_{W}\left[h_{A, l}^{T_{R B}} x_{A, N}+h_{B, l}^{T_{R B}}\left(1-x_{A, n}\right)\right]+ \\
& +\dot{n}_{D}(R+1)\left[h_{A, g}^{T_{1}} y_{A, 1}+h_{B, g}^{T_{1}}\left(1-y_{A, 1}\right)\right]- \\
& -\dot{n}_{F}\left[h_{A, l}^{T_{F}} x_{F}+h_{B, l}^{T_{F}}\left(1-x_{F)}\right]-\right. \\
& -\dot{n}_{D} R\left[h_{A, l}^{T_{1}} y_{A, 1}+h_{B, l}^{T_{1}}\left(1-y_{A, 1}\right)\right]
\end{aligned}
$$

Given the column energy requirements it is possible to calculate the actual condensate flow through the reboiler and ultimately the mass flow through the heat pump compressor. The calculation prerequisite is the knowledge of the actual condensate temperature. In order to obtain this information, design condensate flow evaluation is necessary. The calculation is relatively straightforward, including a simple iteration.

$$
\begin{aligned}
& \dot{Q}_{R B, \text { design }}=\dot{Q}_{R B} \frac{\dot{n}_{V, \text { design }}}{\dot{n}_{V}} \\
& f v a l=P_{\text {out design }}-P_{\text {out }, \text { iter }}
\end{aligned}
$$




$$
\begin{aligned}
& h_{\text {cond, design }}=h_{A, l}^{T_{\text {cond,design }}} y_{A, 1}+h_{B, l}^{T_{\text {cond,design }}}\left(1-y_{A, 1}\right) \\
& h_{\text {comp,design }}= \\
& =\frac{\bar{z} R_{m} T_{\text {in,design }} \frac{\bar{n}}{\bar{n}-1}\left[\left(\frac{P_{\text {out }, \text { design }}}{P_{\text {in, design }}}\right)^{\frac{\bar{n}-1}{\bar{n}}}-1\right]}{\eta_{p}} \\
& h_{\text {in,design }}=h_{A, g}^{T_{i n, \text { esign }}} y_{A, 1}+h_{B, g}^{T_{\text {indesign }}}\left(1-y_{A, 1}\right) \\
& h_{\text {out,design }}=h_{\text {in,design }}+h_{\text {comp,design }} \\
& \dot{n}_{\text {cond,design }}=\frac{\dot{Q}_{R B, \text { design }}}{h_{\text {out }, \text { design }}-h_{\text {cond,design }}}
\end{aligned}
$$

The overall heat transfer coefficient in Eq. (22) is proportional to the mass flow through the heat exchanger. Thus, the design-to-actual heat flux ratio can be expressed as shown in Eq. (23).

$$
\begin{gathered}
\dot{Q}=k A \Delta T \\
\frac{\dot{Q}_{R B, \text { design }}}{\dot{Q}_{R B}}=\left(\frac{\dot{m}_{\text {design }}}{\dot{m}}\right)^{a} \frac{\Delta T_{\text {design }}}{\Delta T} \\
\Delta T=\frac{\dot{Q}_{R B}}{\dot{Q}_{R B, \text { design }}}\left(\frac{\dot{m}}{\dot{m}_{\text {design }}}\right)^{-a} \Delta T_{\text {design }} \\
\Delta T=T_{\text {cond }}-T_{R B}
\end{gathered}
$$

Assuming a constant fraction exponent, the final equation for condensate temperature calculation is as follows:

$$
\begin{gathered}
T_{\text {cond,iter }}=\frac{\dot{Q}_{R B}}{\dot{Q}_{R B, \text { design }}}\left(\frac{\dot{n}_{\text {cond,iter }}}{\dot{n}_{\text {cond,design }}}\right)^{-0,6} \times \\
\times\left(T_{\text {cond,design }}-T_{R B}\right)+T_{R B}
\end{gathered}
$$

Empirical correlations for heat transfer coefficient $(\alpha)$ incorporate its dependence on the Reynolds number as $\alpha \sim \operatorname{Re}^{\mathrm{m}}$ where $\mathrm{m}$ varies between 0.4 and 0.8 depending on particular heat transfer conditions and heat exchanger design. The Reynolds number is directly proportional to mass (molar) flow; heat exchanger duty estimated from the heat transfer equation can therefore be related to the mass flow to the power of $\mathrm{m}$. Average value of $\mathrm{m}=0.6$ was considered in this study - Eqs. (23), (24), (26). Using an analogous approach as in Eqs. (17) to (21), the actual condensate flow was calculated.

$$
h_{\text {comp }, \text { iter }}=\frac{\bar{z} R_{m} T_{1} \frac{\bar{n}}{\bar{n}-1}\left[\left(\frac{P_{o u t}}{P_{1}}\right)^{\frac{\bar{n}-1}{\bar{n}}}-1\right]}{\eta_{p}}
$$

$$
\begin{gathered}
h_{\text {in,iter }}=h_{A, g}^{T_{1}} y_{A, 1}+h_{B, g}^{T_{1}}\left(1-y_{A, 1}\right) \\
h_{\text {out }, \text { iter }}=h_{\text {in,iter }}+h_{\text {comp }, \text { iter }} \\
h_{\text {cond }, \text { iter }}=h_{A, l}^{T_{\text {cond }, \text { iter }}} y_{A, 1}+h_{B, l}^{T_{\text {cond }, \text { iter }}}\left(1-y_{A, 1}\right) \\
\dot{Q}_{R B, \text { iter }}=\dot{n}_{\text {cond, iter }}\left(h_{\text {out }, \text { iter }}-h_{\text {cond,iter }}\right) \\
\text { fual }=\dot{Q}_{R B, \text { iter }}-\dot{Q}_{R B}
\end{gathered}
$$

Combining mass and heat balance of the flash vessel, actual flow through the heat pump compressor (Eq. 35) and vapor generation rate in the flash vessel (Eq. 34) are calculated.

$$
\begin{gathered}
h_{\text {reflux }}=h_{A, l}^{T_{1}} y_{A, 1}+h_{B, l}^{T_{1}}\left(1-y_{A, 1}\right) \\
\dot{n}_{\text {flash }}=\frac{h_{\text {cond }}-h_{\text {reflux }}}{h_{\text {in }}-h_{\text {reflux }}} \dot{n}_{\text {cond }} \\
\dot{n}_{\text {comp }}=\frac{\dot{n}_{V}}{1-\frac{h_{\text {cond }}-h_{\text {reflux }}}{h_{\text {in }}-h_{\text {reflux }}}}
\end{gathered}
$$

Input data for the model simulation in form of average daily operational values were provided by SLOVNAFT a.s. and evaluated for a 500-day period. Typical operational values are depicted in Table 1. Data regarding column and compressor design parameters were obtained from equipment documentation and from the refinery staff and are summarized in Tables 2 and 3 .

Tab. 1. Feedstock properties.

\begin{tabular}{lc}
\hline Parameters & $\begin{array}{c}\text { Numerical } \\
\text { Value }\end{array}$ \\
\hline Typical Mass Flow [t/h] & 8.2 \\
Typical Composition $[\mathrm{mol} \%$ propylene] & 81.2 \\
\hline
\end{tabular}

Tab. 2. Column parameters.

\begin{tabular}{lc}
\hline Parameters & Numerical Value \\
\hline Column Stages & 165 \\
Feed Stage & 46 \\
Head Pressure $[\mathrm{MPa}]$ & 1.17 \\
Bottom Pressure $[\mathrm{MPa}]$ & 1.32 \\
\hline
\end{tabular}

Tab. 3. Design compressor parameters.

\begin{tabular}{lc}
\hline Parameters & Numerical Value \\
\hline Mass Flow [t/h] & 147.7 \\
Inlet Pressure $[\mathrm{MPa}]$ & 1.17 \\
Inlet Temperature $\left[{ }^{\circ} \mathrm{C}\right]$ & 26 \\
Discharge Pressure $[\mathrm{MPa}]$ & 1.78 \\
Discharge Temperature $\left[{ }^{\circ} \mathrm{C}\right]$ & 50 \\
Polytropic Efficiency $[\%]$ & 84.4 \\
\hline
\end{tabular}




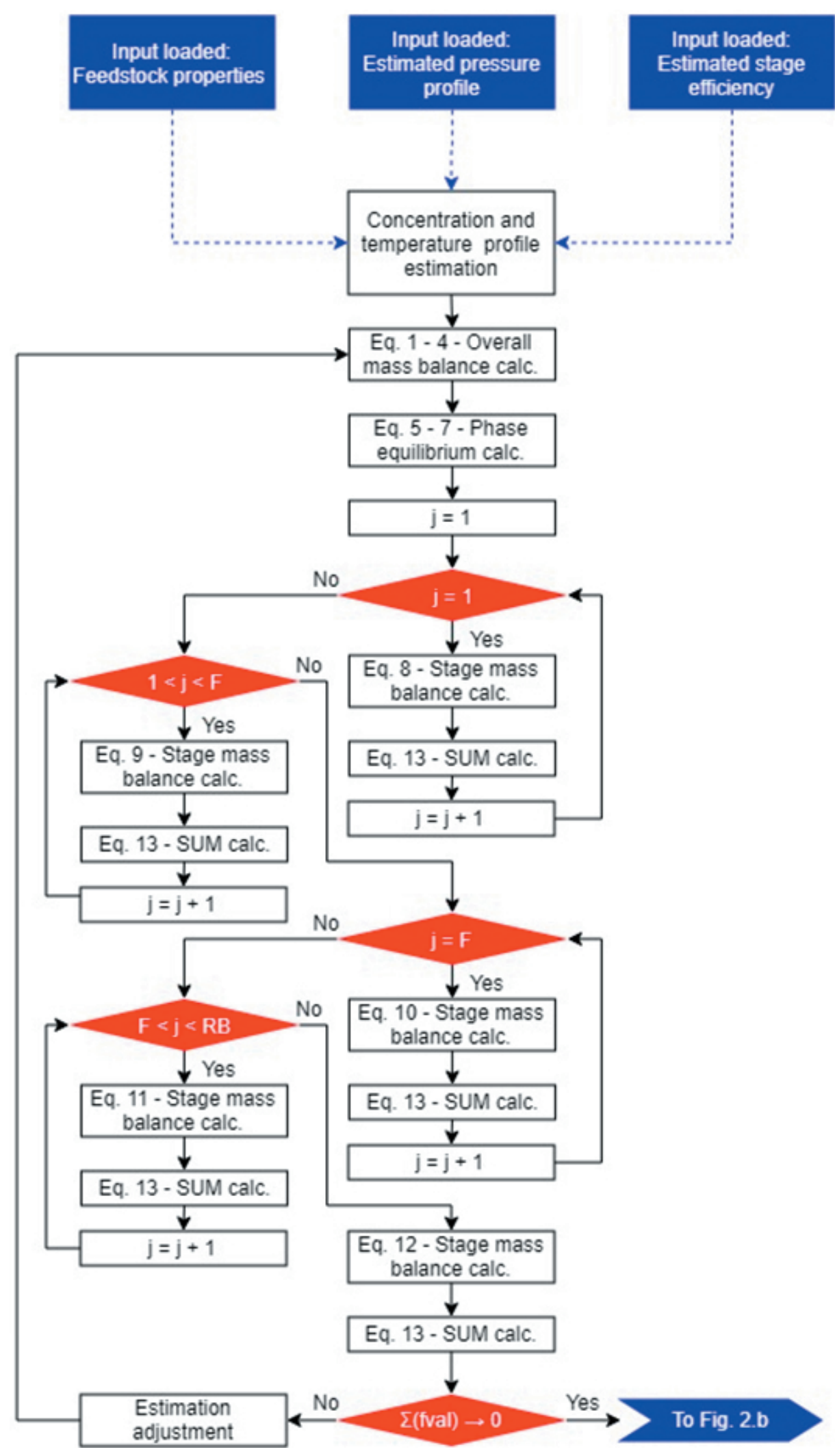

Fig. 2a. Calculation diagram: Column performance.

The following Figs. 2a, 2b serve as calculation process visualization in the Matlab environment, allowing for easy functional module addition, which is important for future work aimed at the compressor and its driving unit performance curves adoption in the model. For each converged iteration loop, the function value fual has to reach the value of $10^{-6}$. Therefore, 15 to 25 iterations on average have to be done regarding the loop complexity. 


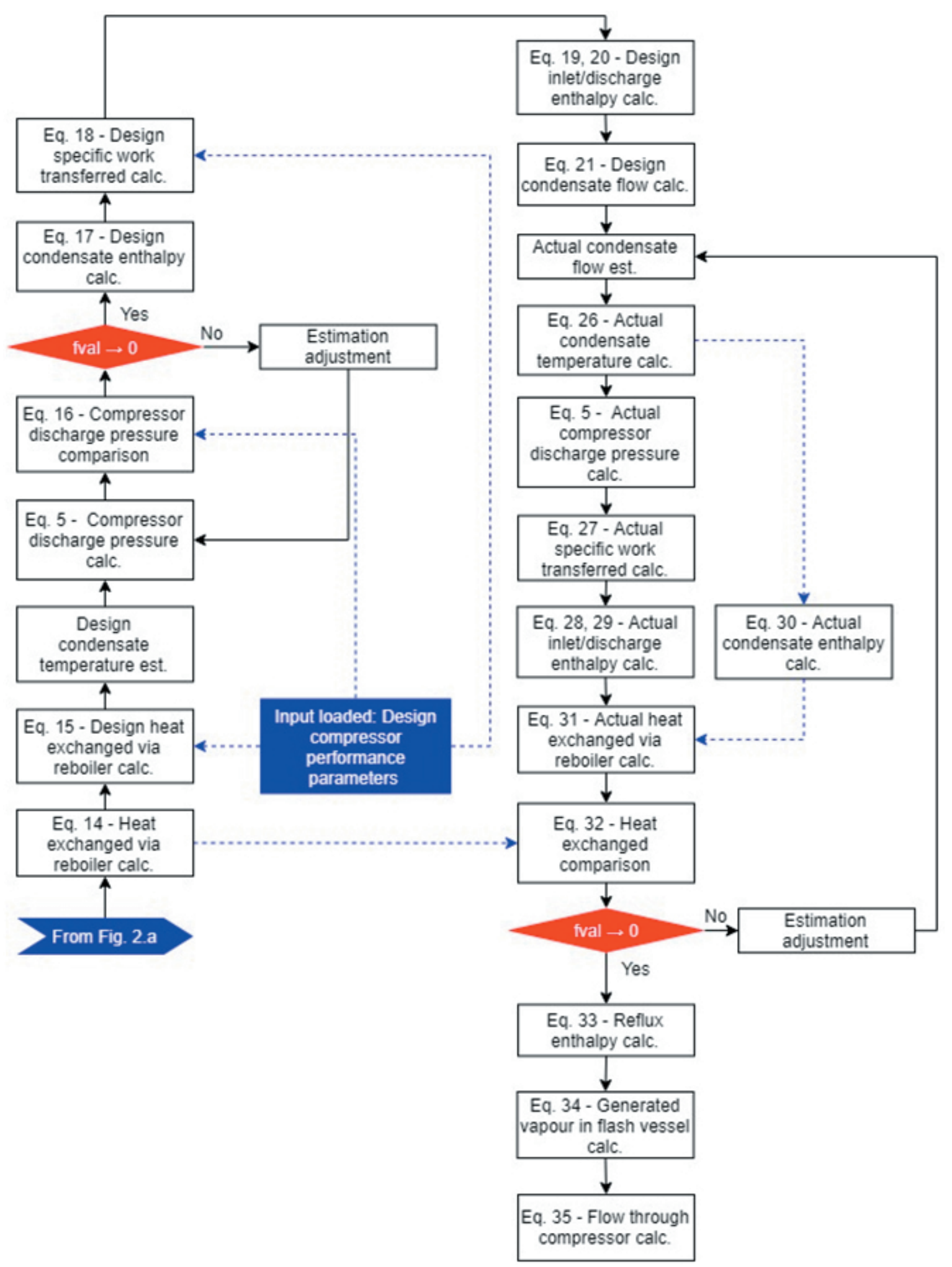

Fig. 2b. Calculation diagram: Heat pump performance.

\section{Results and discussion}

Results of software calculations were reprocessed into charts shown in Figs. 3, 4. Fig. 3 serves for model verification, comparing the calculated and measured mass flow of vapors compressed in the heat pump compressor. Very good agreement can be seen during periods with the measured mass flow above $100 \mathrm{t} / \mathrm{h}$. With decreasing vapors mass flow, the calculated and model based values diverge; the calculated ones being by 20 to $30 \mathrm{t} / \mathrm{h}$ lower than the measured ones. Explanation for such discrepancy was obtained by studying the compressor performance curves that have not been a part of the calculation model - the 
compressor design limits proper compressor operation above $100 \mathrm{t} / \mathrm{h}$ of compressed vapors to avoid the surge occurrence danger. At lower column feeds, mass flow of vapors below $100 \mathrm{t} /$ his sufficient to achieve the desired product purity (99.5 to $99.6 \%$ wt. propylene). This, however, requires regulated opening of the compressor antisurge by-pass to increase the compressed vapors mass flow. In the end, a part of the compression work is wasted to recompress the by-pass stream, which lowers the heat pump energy efficiency.

An alternative approach, as documented in Fig. 4 and preferred by staff, allows for the production of even higher purity propylene product (around $99.7 \%$ wt.); due to very close propane and propylene molar masses, the propylene molar and weight fraction in the propylene product is almost identical (Fig. 4) at no additional cost: the column reflux ratio can be increased above the usual value during periods with lower column feed. Therefore, sufficient compressed vapors mass flow through the heat pump compressor is retained and the antisurge by-pass valve can remain closed.
The applied compressor load controlled by the frequency converter couples the compressor discharge pressure and throughput. The possibility of compressor discharge pressure optimization is unused by staff at the moment keeping the discharge pressure at almost constant value. However, optimization would yield specific compression work decrease as well as a modest decrease of the minimum compressor throughput needed to avoid surge occurrence. This possibility will be considered in further work.

An alternate means of compressor load control - by a variable inlet guide vane - seems to be more suitable in this application as it allows operating the compressor in a broader throughput range than the frequency converter while decoupling the discharge pressure and throughput control. An analysis of additional implementation possibilities of such compressor load control is out of the scope of this paper.

It can be concluded that increased product purity at zero incremental cost can be achieved in the studied system during periods with lower C3 fraction feed

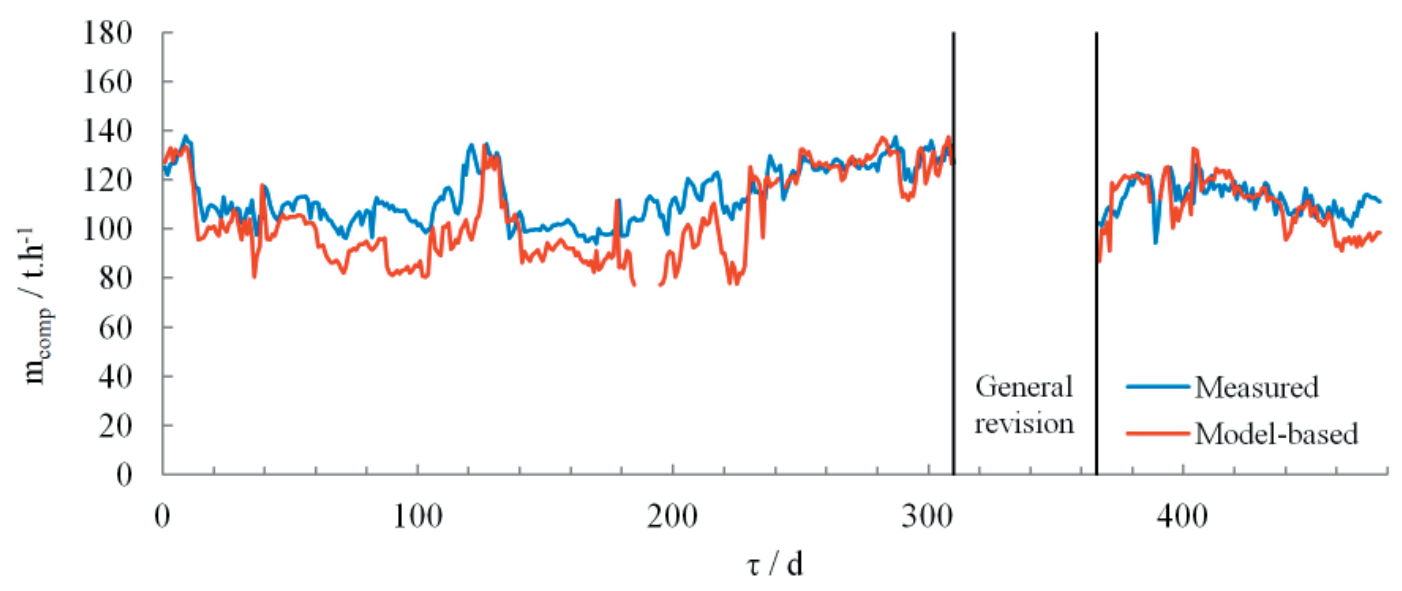

Fig. 3. Calculation model verification - comparison of calculated and measured values of compressed vapor mass flow in the heat pump compressor.

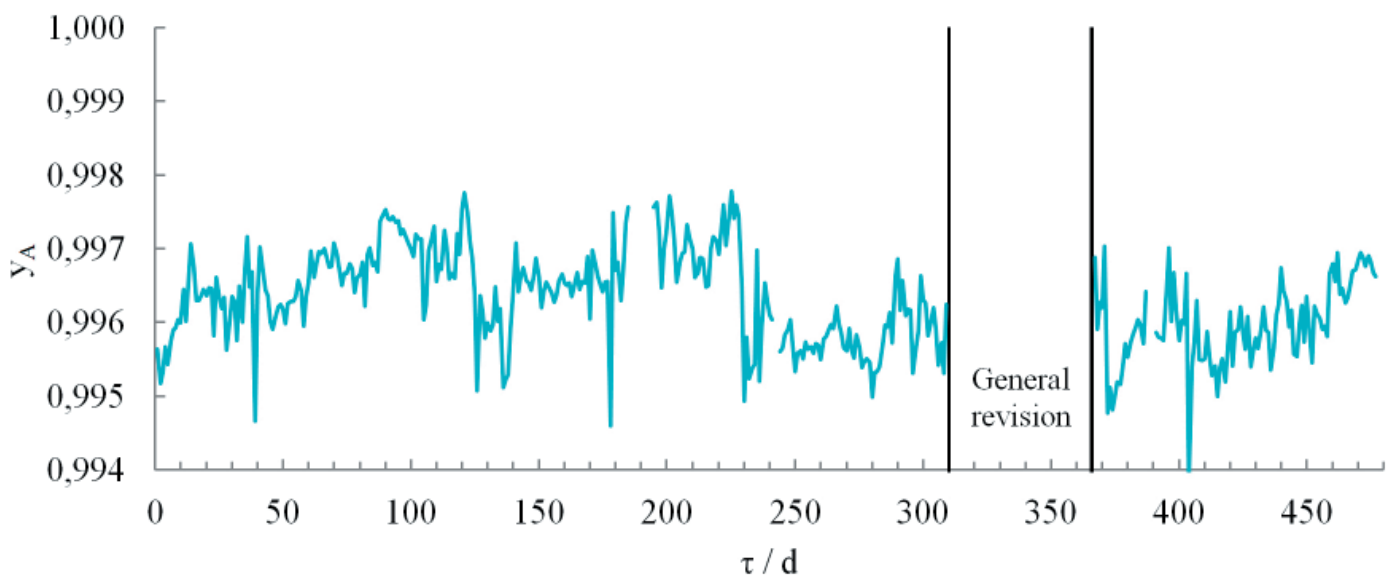

Fig. 4. Achievable propylene product purity. 
to the splitter, allowing for production costs reduction in the polypropylene production plant, as lower amount of inert (propane) has to be removed from the reaction gas purification section in such a case. Alternative point of view yields that increasing the C3 splitter load above a certain value may limit the achievable product purity which is an important fact to be taken into account when evaluating the C3 fraction production increase possibility in the FCG unit.

\section{Conclusions}

The presented paper provides a comprehensive overview of industrial C3 fraction splitter modeling incorporating a heat pump. The model has been developed based on the system layout and taking into account the system mass and heat balance as well as the vapor-liquid equilibrium and compression work calculation. Comparison of model calculated and measured vapor mass flow compressed in the heat pump compressor showed very good agreement. Periods with differences in these values stemmed from the compressor antisurge protection system activated at lower vapor throughputs. This remains a challenge to be addressed in future work together with the heat pump driver performance assessment. It is expected that implementation of these equipment limitations and features in the C3 splitter mathematical model will enable calculating the incremental C3 fraction splitting costs reliably, thus providing a tool for system operation optimization.

\section{List of symbols and abbreviations}

a exponent in equations (23) and (24); $\mathrm{a}=0.6[-]$

$\mathrm{C}_{1}$ to $\mathrm{C}_{5}$ constants used in pure substance saturated vapor pressure calculation - equation (5)

foal function value [-]

$h \quad$ molar enthalpy $\left[\mathrm{kJ} \mathrm{kmol}^{-1}\right]$

$k \quad$ overall heat transfer coefficient

$\left[\mathrm{kW} \mathrm{m}^{-2} \mathrm{~K}^{-1}\right]$

$\dot{m} \quad$ mass flow $\left[\mathrm{kg} \mathrm{s}^{-1}\right]$

$\dot{n} \quad$ molar flow $\left[\mathrm{kmol} \mathrm{s}^{-1}\right]$

$\bar{n} \quad$ average value of polytropic coefficient [-]

$P \quad$ pressure $[\mathrm{kPa}]$

$P^{0} \quad$ saturated vapour pressure of pure sub-

stance $[\mathrm{kPa}]$

$\dot{Q} \quad$ heat flux $[\mathrm{kW}]$

$R \quad$ reflux ratio [-]

$R_{m} \quad$ universal gas constant $\left[\mathrm{kJ} \mathrm{kmol}^{-1} \mathrm{~K}^{-1}\right.$ ]

$T \quad$ thermodynamic temperature [K]

$x \quad$ molar fraction in liquid phase [-]

$y \quad$ molar fraction in gas phase [-]

$\bar{z} \quad$ average value of compressibility coefficient [-]
$\Delta T \quad$ mean temperature difference $[\mathrm{K}]$

$\eta_{p} \quad$ polytropic compression efficiency [-]

\section{Subscripts}

$A, B \quad$ components (propane and propylene)

comp related to compressor

cond related to condenser

D distillate (stream)

design design (operational or construction) parameter

F $\quad$ feed (stream)

flash related to flash vessel

$g$ gas phase

i component

in inlet conditions

iter value in iterative calculation

j $\quad$ stage numbering

$l \quad$ liquid phase

$n \quad$ stages above the feed stage

$m \quad$ stages below the feed stage

out outlet (discharge) conditions

${ }_{R B} \quad$ related to reboiler

reflux reflux (stream)

${ }_{V} \quad$ vapor (phase)

${ }_{W} \quad$ waste (stream)

\section{Superscripts}

$\mathrm{T}$ calculated at temperature $\mathrm{T}$

\section{Acknowledgements}

The authors would like to express many thanks to all SLOVNAFT a.s. employees who contributed to the final scope and form of this paper. This work was financially supported by the Slovak Scientific Agency, Grant No. VEGA 1/0659/18 and by the Slovak Research and Development Agency, Grant No. APVV-15-0148. The authors also gratefully acknowledge the support from the project Science and Technology Park STU Grant no. ITMS26240220084, co-financed by the European Regional Development Fund.

\section{References}

Alhajji M, Demirel Y (2015) Energy and environmental sustainability assessment of a crude oil refinery by thermodynamic analysis. International Journal of Energy Research 39: 1925-1941.

Al-Rowaili FN, Ba-Shammakh MS (2017) Maximisation of an oil refinery profit with products quality and $\mathrm{NO}_{2}$ constraints. Journal of Cleaner Production, 165: 1582-1597.

Danilov Y, Sinkevich I, Lavrova I, Mardupenko A, Tulskaya A (2018) Energy saving technologies in the petroleum refining processes, Petroleum and Coal 60(1): 128-133.

DeCarolis J, Daly H, Dodds P, Keppo I, Li F, McDowall W, Pye S, Strachan N, Trutnevyte E, Usher W, Winnig H, Yeh S, Zeyringer M (2017) Formalizing best practice 
for energy system optimization modeling. Applied Energy, 194: 184-198.

Demirel Y (2004) Thermodynamic Analysis of Separation Systems. Papers in Thermal Mechanics, 39: 3897-3942.

EIA (2016) International Energy Outlook 2016. Washington, USA: Energy Information Administration, U.S. Department of Energy. https://www.eia. gov/outlooks/ieo/pdf/0484(2016).pdf. Accessed on 15. 1.2019.

Fonyo F, Benkö N (1998) Comparison of various heat pump assisted distillation configurations. Chemical Engineering Research and Design, 76(3): 348-360.

Gadalla MA, Abdelaziz OY, Kamel DA, Ashour FH (2015) A rigorous simulation-based procedure for retrofitting an existing Egyptian refinery distillation unit. Energy, 83: 756-765.

Hasanbeigi A, Price L (2010) Industrial Energy Audit Guidebook: Guidelines for Conducting an Energy Audit in Industrial Facilities. https://eetd.lbl.gov/ sites/all/files/publications/lbl-3991e-industrial-auditguidebookoct-2010.pdf. Accessed on 3. 9. 2018.

Chudinova AA, Buchatskaya NI, Podgornyi VV, Gavrikov AA, Ivashkina EN, Dolganova IO (2016) Increase of efficiency isopropylbenzene manufacturing with use of integrated mathematical models. Petroleum and Coal, 58(2): 155-160.

Chuzlov VA, Molotov KV (2016) Development of computer modeling system as a tool for light naphtha isomeration improvement. Petroleum and Coal, 58(1): $47-55$.

Kazemi A, Hosseimi M, Mehrabani-Zeinabad A, Faizi V (2016) Evaluation of different vapor recompression distillation configurations based on energy requirements and associated costs, Applied Thermal Engineering, 94: 305-313.

Li J, Xiao X, Boukouvala F, Floudas ChA, Zhao B, Du G, Su X, Liu H (2016) Data-Driven Mathematical Modeling and Global Optimization Framework for Entire Petrochemical Planning Operations. AIChE Journal, 62: 3020-3040.
MOL (2016) MOL GROUP strategy 2030, business presentation. https://molgroup.info/strategy2030/. Accessed on 21. 1. 2019.

Morrow III WR, Marano J, Hasanbeigi A, Masanet E, Sathaye J (2015) Efficiency improvement and $\mathrm{CO}_{2}$ emission reduction potentials in the United States petroleum refining industry. Energy, 93: 95-105.

Perry RH et al (1997) Physical and Chemical Data.In: Perry's Chemical Engineers' Handbook $-7^{\text {th }}$ Edition, London, McGraw - Hill Professional.

Vall J (2011) Industry and its impact on the environment in Slovak republic in 2011 - sector report. (in Slovak) Slovak Environment Agency Banská Bystrica. https:// www.enviroportal.sk/uploads/report/sprava-priem2013-final.pdf. Accessed on 16. 1. 2019.

Variny M, Blahušiak M, Mierka O, Kováč N (2013) Analysis of energy effectiveness of C3 fraction splitting techniques implemented in Slovnaft refinery. In: Proceedings of the $4^{\text {th }}$ International Conference on Chemical Technology ICCT 2013, Mikulov, Česká republika: $78-82$.

Variny M, Mierka O, Gašparovič L (2015) Experiences and future prospects of GRUCON - SLOVNAFT cooperation in energy auditing field. In Proceedings of the $42^{\text {nd }}$ International Conference of SSCHE. Bratislava: Slovak Society of Chemical Engineering, 2015: 351-358.

Vilarinho AN, Campos JBLM, Pinho C (2016) Energy and exergy analysis of an aromatics plant. Case Studies in Thermal Engineering, 8: 115-127.

Worell E, Corsten M, Galitsky Ch (2015) Energy Efficiency Improvement and Cost Saving Opportunities for Petroleum Refineries. An ENERGY STAR ${ }^{\circledR}$ Guide for Energy and Plant Managers. A document prepared for The United States Environmental Protection Agency. www.energystar.gov/industry. Accessed on 17. 1. 2019.

You X, Rodriguez-Donis I, Gerbaud V (2016) Reducing process cost and $\mathrm{CO}_{2}$ emissions for extractive distillation by double-effect heat integration and mechanical heat pump.Applied Energy, 166: 128-140. 